Jones, M. and Williams, M. L. (2013) 'Twenty years on: lesbian, gay and bisexual police officers' experiences of workplace discrimination in England and Wales', Policing \& Society, 25 (2): 188-211. http://dx.doi.org/10.1080/10439463.2013.817998

\title{
Twenty years on: lesbian, gay and bisexual police officers' experiences of workplace discrimination in England and Wales
}

\author{
Matthew Jones ${ }^{\mathrm{a} *}$ and Matthew L. Williams ${ }^{\mathrm{b}}$
}

${ }^{\mathrm{a}}$ School of Humanities and Social Science, Liverpool John Moores University, Liverpool, UK;
${ }^{\mathrm{b}}$ School of Social Sciences, Cardiff University, Cardiff, UK

Twenty years ago Mark Burke's pioneering research into homosexuality and policing evidenced widespread prejudice and hostility toward lesbian, gay and bisexual police officers in nine forces across England and Wales. These serving officers were felt to represent the most serious kind of contamination and threat to the integrity of the British Police Service by their heterosexual colleagues. Twenty years on this research, which represents one of the largest ever surveys of LGB police officers in England and Wales $(\mathrm{N}=836)$, evidences that just under one-fifth reported experiencing discrimination, with those in small and large forces, those in senior ranks and non-uniformed positions, and those who identify as gay male and Black, Minority Ethnic experiencing the highest levels of victimisation in training, deployment and promotion. Like Brown and Woolfenden, the authors conclude that a central aim of the diversity reform agenda must be a renegotiation of the psychological contract between staff and the organisation. A relational setup must be sought where mutual expectations of exchange are established and efforts are made to create a rich working environment that draws upon and invests in the subjective and intersubjective identity characteristics of LGB police officers.

Keywords: Lesbian; gay and bisexual police officers; sexual orientation; employment discrimination

\section{Introduction}

In recent decades political, social and legislative re-configurations have radically transformed the contemporary experiences of lesbian, gay and bisexual (LGB) individuals living in the UK. Communities and individuals who were once unshielded and left in social abjection are now afforded opportunities to become active, empowered and protected citizens (Weeks 2007). The relationship between the police and LGB communities can be said to have taken a similar journey. Historically, relations were marred due to a variety of reasons. In particular, the criminalisation of homosexuality and associated sexual acts between males and overpolicing of these offences in the 1970s and 1980s ensured that the police and LGB communities were opposed for many decades (Seabrook 1992, Moran 2012). Consequences of this fraught relationship included police ignorance of homophobic and same-sex partner violence (Derbyshire 1990, GALOP 1998), poor crime reporting behaviours (NAGS 1999), fear of repeat victimisation (Lewisham Gay 
Alliance 1992) and concern about coming out to the police (Mason and Palmer 1996). The distance between the police and LGB communities had become so great that the Home Office identified, in their thematic inspection on police integrity in 1999, that some forces were failing in providing an adequate service to marginalised LGB communities (HMIC 1999). Four years later, the decriminalisation of various same-sex sexual behaviours under the Sexual Offences Act 2003 saw a sea change in policing practices and subsequent relations with LGB communities (see Williams and Robinson 2004 for an overview).

Given the socially embedded and sensitive nature of policing, the wider social diversity agenda has permeated into the organisation, bringing about critical reviews on a national scale and paradigm shifting changes that directly challenge the historically embedded supremacy of informal occupational cultures. At the turn of the millennium, the politicisation of diversity within policing (Loftus 2009) resulted in the introduction of a plethora of initiatives aimed at the recruitment, retention and promotion of individuals from minority social groups. Yet, despite fresh empirical inquiry into the occupational experiences of women and ethnic minority officers within these new policing climates (Brown and Heidensohn 2000, O'Neill and Holdaway 2007, Rabe-Hemp 2008, Holdaway 2009), the experiences of LGB police officers has been largely neglected for two decades (see Burke 1993). The aim of this article is to address this imbalance by reporting the results of the largest national survey of LGB police officers to be conducted in England and Wales. Specifically, drawing on a sample of 836 LGB officers from all 43 forces, this paper provides an overview of the extent of homophobic discrimination from within the organisation in relation to three employment areas: training, deployment and promotion. Twenty years on we compare these findings with those in Marc Burke's original research and discuss the extent to which the rhetoric underpinning police cultural reform has impacted upon the working lives of LGB police officers.

\section{The experiences of LGB police officers: past research}

Now 20 years old, Marc Burke's $(1993,1994)$ research has been the only to exclusively examine the occupational experiences of LGB police officers in England and Wales. His findings presented a rather austere construct of the workplace realities faced by LGB police officers - branded as deviant by the heterosexual dominant and as representing the most serious kind of contamination and threat to the integrity of the British Police Service (Burke 1994). As a consequence, those LGB officers who chose to openly disclosed their sexual orientation at work, or who are merely suspected of non-heterosexuality, reported prejudice and discrimination from across the police organisation. Examples of the former included being subjected to derogatory discourse; professional humiliation; physical violence and the refusal from some heterosexual officers to work in close proximity with LGB officers. In regard to discrimination, respondents reported challenges and resistance within the recruitment process and during training, inequitable allocation of duties, and bars to promotion and development.

Burke rationalised this antagonism between homosexuality and policing on two grounds. First, common social stereotypical constructions of homosexuality with effeminacy, weakness and sexual deviance were considered to oppose and challenge the conservative, conformist and role appropriate behaviours that had become 
synonymous with the dominant yet unwritten masculinist subcultural constitution that underpinned police practices. Those who deviated or threatened the integrity of this occupational standard forfeited their fraternal membership and the protections that it afforded. Second, Burke presented a criminality hypothesis as a persuasive justification to resistance and exclusion. The fresh memory of homosexuality as illegal left an imprint of 'homosexuality as deviant' in the minds of heterosexual officers. This was compounded by the history of occupational socialisation that legitimised the LGB community as a target of professional suspicion, resulting in the over-policing of public LGB sex environments and drug consumption in LGB nighttime establishments.

In light of such hostility, Burke identified the double-life strategy opted for by the majority of the LGB officers - intentionally disguising their sexual orientation through a strict and premeditated performance of heterosexuality at work throughout their careers. Yet, although a common path, this practice brought with it serious cautionary risks - namely damage to mental health and stability, an inability to give maximum attention to police duties, difficulties in forming professional relationships and high levels of withdrawal from the force before pensionable age due to psychological breakdown. Despite providing an intellectually intriguing insight into the occupational experiences of LGB officers, it is clear, from a general reading of contemporary police reform agendas and associated cultural shifts, that the occupational policing framework on which Burke's research was built has now evolved somewhat, giving rise to claims that his thesis fails to provide a valid insight into the working lives of LGB police officers today.

Internationally, empirical work in this area has witnessed a recent resurgence. Of particular note are the research contributions made by academic colleagues in the US. For example, Belkin and McNichol (2002) explored the occupational experiences of LGB officers within the San Diego Police Department, reporting considerable improvements in their working environments. Yet, despite this, instances of barred promotional opportunities, resentment from heterosexual colleagues and derogatory discourse were widely reported. Bernstein and Kostelac's (2002) survey of police officers in South West USA showed patterns of resistance to the employment of LGB officers with $69 \%$ of their respondents reporting that these individuals do not belong in law enforcement and $85 \%$ asserting that gay men would not be able to perform their job as well as others. Interestingly, Colvin (2008) found that instances of discrimination occurred in areas where supervisory discretion was highest, with LGB officers citing adverse treatment during annual evaluations, workload allocation and support for promotion and development. These factors are further explored by Colvin (2012) in his comparative study of LGB officers' operational utility in the UK and USA. Further afield, Praat and Tuffin's (1996) research in New Zealand found that the discursive constructions of homosexuality by heterosexual colleagues cast gay male officers as deviant and effeminate making them inappropriate candidates for a policing career. Thus, with growing international insights from alternative police systems, demand continues to grow for similar insights into the current occupational climate in England and Wales.

\section{Reconfigured attitudes towards diversity and LGB officers}

It has been argued that the police failed to adequately respond to the emergent recognition of the diversity of British society in the latter part of the twentieth 
century. As a consequence, it took the critical lens of both Scarman (1981) and Macpherson (1999) - who examined police relationships with minority communities in England and Wales, respectively, before and during the Brixton riots and following the murder of the black schoolboy Stephen Lawrence - to call time on antiquated and disconnected police practices, by igniting a period of institutional reflection and organisation reform that would dramatically change the face of traditional policing (Hall et al. 2009, Reiner 2010). Scarman (1981) and Macpherson (1999) collectively highlighted the failure of the police to accommodate and reflect social difference due to the restrictions of their monolithic and antiquated practices - a reality that had and continued to lead to substantial police failures and ineffectiveness. Although substantively concerned with relationships and conduct between the police and Black, Minority Ethnic (BME) communities, these reports led to the audit and scrutiny of police diversity practices more broadly - including gender and sexuality policing issues (McLaughlin, 2007). Consequently, the new millennium brought with it a plethora of reform initiatives that placed a legal, business and ethical case for diversity and the aim for the police to reflect the diverse communities that they serve at their core (HMIC 2003, Clements 2008).

Against this backdrop of positive evolvement, tragically, on 30 April 1999, the LGB community was thrown into disarray when a popular gay pub in the district of Soho, London, was nail bombed by David Copeland. Directly afterward, as a result of the unwillingness of LGB witnesses to engage with the police due to their historically antagonistic relationship, the Metropolitan Police called upon their LGB officers to come forward and engage with this reluctant community. This radical manoeuvre allowed for sufficient evidence to be collected to prosecute Copeland for his crimes and to reassure the rest of the LGB community about their safety. Although tragic, the events of April 30 did provide an emotive example of how the subjective and intersubjective identity characteristics of LGB officers could be drawn upon as an organisational resource.

Subsequently the integration of LGB officers into the new organisational strategy of diverse policing became a key policy within the police reform agenda (HMIC 2003). Yet, aware that transforming the status of LGB officers from deviant and an organisational contaminant would be difficult, the police set about introducing a wide portfolio of initiatives to break down negative attitudes and increase LGB representation in the ranks. Examples over the last decade include (1) the active recruitment of LGB candidates through marketing campaigns and engagement initiatives, (2) the expansion of the national GPA and local gay staff networks and (3) the establishment of LGB and transgender liaison officers (see Godwin 2007 for further discussion).

\section{In pursuit of a discrimination-free organisation}

A central aim of this reform agenda has been the eradication of draconian police subcultural practices and the creation of a new contemporary organisational culture within which the concept of difference and the benefits it affords to the organisation is embraced, encouraged and protected. Thus, police frameworks have been introduced nationally that promote and support this mission of equality and diversity across the ranks, so that minority officers feel comfortable to utilise and embed their subjective and intersubjective identity characteristics into the 
role without fear or experience professional recourse or institutional bias. This anti-discrimination mission has been underpinned by a tripartite framework of measures as follows.

\section{Legal protection}

Externally, LGB individuals have been afforded increased legal protection in the workplace since 2003. More recently, The Equality Act 2010 brought together over 116 separate pieces of discrimination legislation into a single unifying law. The aim was to simplify and strengthen the law as applied to persons with "protected characteristics' (namely: age, disability, gender reassignment, marriage and civil partnership, race, religion or belief, sex and sexual orientation). Broadly, the Act prohibits direct discrimination. In the context of work, this means that employers must not discriminate as to who they hire, the terms of employment of their employees, access to promotion, training benefits and so on. Discrimination at work could lead to an Employment Tribunal awarding compensation or making a recommendation (e.g. that the discriminatory behaviour stops). The Act also allows for what it terms positive discrimination by employers: examples of this would include the recruitment of a person with a 'protected characteristic' where that characteristic is underrepresented in the workforce and the relevant person is of equal merit to other candidates; or positive action: the taking of special measures to alleviate disadvantage, such as a management training programme solely for LGB people in a workplace where they are underrepresented at the higher management levels.

\section{Revised regulation of police conduct standards}

In 2006, the Home Office launched a consultation into the police conduct rules (Home Office 2006). The proposals stemming from the consultation, including respect for diversity as a key professional expectation, were ratified within The Police (Conduct) Regulations 2008 followed by the establishment of professional standards directorates within police forces nationally. The new code places factors such as respect and courtesy, honesty and integrity, personal autonomy, lawfulness and professional equity at the core of police organisational ethics. This new system provides a platform and process through which officers can formally record discriminatory behaviour, allocates specialist internal resources to investigate such claims and includes the power and remit to impose professional discipline upon those who are found to act outside of the required standards.

\section{Formal recognition of diversity as an organisational priority from the top}

The importance of organisational diversity, the eradication of discriminatory behaviours and corresponding commitment of forces nationally to bring about meaningful reform has been symbolically demonstrated by investment in several LGB initiatives including the establishment of diversity as a central performance indicator; the allocation of budgets to market police recruitment to LGB communities; making diversity training compulsory for all officers; the attendance of senior officers at Gay Pride and LGB events; the establishment of positive action promotion initiatives and tailored development support and the embedding of 
respect for diversity as a key competency for recruitment and promotion processes. But despite such efforts, the effectiveness and translation from policy to practice of contemporary anti-homophobic discrimination initiatives has yet to be empirically explored. Accordingly, this article examines discrimination towards LGB police officers in constabularies across England and Wales in order to provide critical reflections and an evidence base the future policy development.

\section{Theoretical framework}

The theoretical framework of this paper rests on the conceptualisation that both 'sexuality' and 'police organisational culture' are social constructs. Although widely considered to be biologically determined, sexuality in organisational settings is regulated by the subjective individual, whose internal dialogue and willingness to transpose the internal sexuality into external personality traits and social performance is shaped by external social climate, location within wider formal social frameworks and lived experience within the larger social milieu. 'The Police' are a prescribed and tangible social institution - representatives of the people who through social licence and a territorial framework across England and Wales regulate and monitor social deviance on behalf of the state. To explore responses to homosexuality within the police, we argue, require an understanding of the nature, power and conflict between organisational and occupational cultures beyond the monolithic in order to reflect the heterogeneous and diverse realities of contemporary policing within which LGB police officers are professionally located.

On this premise, the portfolio of organisational initiatives that aim to attract, accommodate and protect LGB police officers in the post-Macpherson era of policing discussed above are part of a moral organisational strategy, determined by policy-makers and senior managers, which collectively contribute to and characterise a modern, inclusive and societally reflective police organisational culture. These are the idealist, ethical and centralised foundations on which standards of formal police conduct rules rest. These standards are rhetorically free from discrimination, oppose and challenge prejudice and include paths of recourse for those who breach or fail to achieve the desired level of professionalism. However, the effectiveness of these standards is hindered by their forced synergy with historically embedded informal beliefs and attitudes prescribed by police occupational subcultures (Holdaway 1983, Manning 1989, Sklansky 2006, Brown 2007, Reiner 2010). The tacit rules that emerge from such beliefs are central to the establishment of subculture which is significantly persuasive and influential among police officers - more than observed by any other profession (Van Maanen 1973). It is often cited as the source and justification for resistant, bigoted and prejudiced attitudes and behaviours (Brown 2007, Sklansky and Marks 2008). As such it is often described as masculinist, heteronormative and resistant to difference, and as posing the largest threat to new organisational frameworks and the successful integration of LGB officers into contemporary police environments (Burke 1993). In this vein, police organisational discrimination is seen to occur when conflicting informal subcultural beliefs and practices adversely impact and influence the application and administration of formal organisational frameworks, processes and initiatives. 
Given that sexuality, policing and associated cultures are part of a social construct, it follows neither are universal and monolithic. Each is determined by situational factors and the subjective interpretation by the individual. Thus, factors that underpin discrimination within police settings vary at a minimum according to force type, gender, ethnicity and position within the formal organisational hierarchy and type of police work. Using geography/force type as an example, Fyfe (1991) argues that policing cannot be understood in isolation from the contexts in which it is, quite literally takes place, calling for an understanding of policing according to national, regional and local scales. Mawby and Yarwood (2010) examine policing in rural constabularies and settings, identifying how community makeup and exposure to diversity can impact police environments, human resource demographics and the nature of police forces in such settings. In this regard, Neal (2002) and Holloway (2005) discuss social resistance to 'otherness' in rural settings and postulate how predominately White heterosexual communities can impact the human composition of forces and police priorities outside of the metropolis. Furthermore, Bland et al. (1999) and Brown and Heidensohn (2000) show how the experiences of women and BME minorities in the police service are not homogeneous, and that subjective and intersubjective variations in minority identity characteristics are pivotal in shaping the variety of occupational outcomes. Research by Williams and Robinson (2004, 2007) and Stonewall (2008) shows exposure to homophobic victimisation varies significantly within LGB identities and is shaped further by the intersection of other minority characteristics (such as BME). As a consequence, it is only through a holistic and heterogeneous examination of sexuality, police setting, process and cultures that a valid analysis of discrimination and its causes can be determined. To this end, this study incorporates a range of measures that account for the variety of factors that might shape the experiences of LGB police officers, including force, job and personal identity characteristics. Next, we delineate our hypotheses in relation to this theoretical framework.

\section{Hypotheses}

H1: Based on aforementioned research that evidences discrimination varies by force characteristics (Fyfe 1991, Neal 2002, Holloway 2005, Yarwood and Mawby 2010), we postulate that perceived experience of LGB discrimination across three employment areas (training, deployment and promotion) will vary by force size ${ }^{1}$;

$\mathrm{H} 2$ : We also postulate that perceived experience of discrimination will vary by the job characteristics of rank and uniformed/non-uniformed. This is based on research that suggests the experience of minorities working as police officers across ranks and divisions is not homogeneous (Burke 1994, Bland et al. 1999, Brown and Heidensohn 2000);

H3: Based on empirical evidence that demonstrates experience of discrimination varies sexual orientation type (Burke 1994, Williams and Robinson 2004, 2007, Stonewall 2008), we suppose Gay Male officers will be significantly more likely to experience discrimination in their occupational role compared to Gay Female, Bisexual Female and Bisexual Male officers;

H4: The research cited in $\mathrm{H} 3$ also shows that the intersectionality of minority identities can increase the risk of victimisation. Based on this pattern, we postulate that officers with 
multiple minority identities (in our case BME LGB officers) will be more likely to experience each type of discrimination (in isolation and in combination).

\section{Methods and analysis}

\section{Data}

This paper reports on the largest survey that exclusively focuses on LGB police officer perceived experiences of occupational discrimination in England and Wales. The primary data used in this analysis were derived from an online survey of 836 serving LGB police officers from the 43 police services in England and Wales. The Bristol Online Survey tool ${ }^{2}$ was used to design and distribute the questionnaire via email. The survey posed questions on perceived experiences of discrimination in three areas of employment: training, deployment and promotion. It also posed questions on force, job and personal characteristics, including force size, type of deployment, length of tenure, rank, sexual orientation, relationship status, ethnicity, whether respondents disclosed their sexual orientation at work and membership to local and national LGB employment groups (see Table 1). Access was gained to LGB officers via the Police Federation and the Association of Chief Police Officers as well as local police service LGB staff networks. The use of online media in social research is now well established and can yield results for exploratory research in a short period of time (Fielding et al. 2008). Non-probability sampling was employed to derive the sample of respondents. While sample bias is a fundamental shortcoming of non-probability sampling, Meyer and Wilson (2009) notes that this is often the only option available to researchers embarking on exploratory research with LGB populations. Furthermore, as the hypotheses tested in this analysis are concerned with the existence of inter-variable relations and strengths of association, the use of non-probability sampling does not fundamentally weaken the design of the study (Dorofeev and Grant 2006). Moreover, our study is principally concerned with 'soft' measures (perceptions of occupational discrimination), which have no absolute validity (they cannot be compared with any authoritative external measure). This classification resonates with the existing Home Office and CPS definition of hate crimes and incidents, which is centred on victim perceptions and not evidential criteria. Meyer and Wilson (2009) caution that sampling bias can still affect hypothesis testing if a sample is significantly uncharacteristic of the target population. Selective targeting was employed during survey recruitment to mitigate this potential problem. In particular, we were aware of the need to map our sample onto recent police service strength (PSS) statistics (in particular rank, gender and BME) where possible.

The research was conducted in line with the ethical guidance established by the Association of Internet Researchers. ${ }^{3}$ Given the nature of the research topic, the researcher made efforts to establish informed consent via the introduction page to the online survey. The research aims and objectives were clearly expressed and all respondents were informed that the data produced would be anonymised and would remain confidential. 


\begin{abstract}
Measures
Dependent variables

Two types of dependent variable were used in the models reported. Binary response variables (Yes/No) on the perceived experience of occupational discriminatory acts (types: training, deployment and promotion) were used in logistic regression models. The second variable type measured the breadth of discrimination experienced by certain LGB officers, in the form of a count. This count variable was derived from the number of types of discrimination experienced over the tenure period of responding LGB officers. The majority of the sample reported experiencing none of the types of discrimination (83\%). Of those that did $12 \%$ experienced one type, compared to $6 \%$ who experienced more than one type. This outcome variable was entered into a zero-inflated Poisson (ZIP) regression model. This dependent variable resembled a Poisson distribution, exhibiting a positive skew.
\end{abstract}

Predictor variables. Table 1 reports on the descriptive statistics for the predictor variables used in the ordered regression analyses reported later in the paper.

\title{
Force characteristics
}

A force size variable was used in the analysis. This was an aggregate variable matched to the PSS statistics on full time equivalent count (Dhani 2012). Due to regression requirements, dummies were derived from this variable and medium size force was used as the reference category.

\section{Job characteristics}

Several survey items elicited information on LGB police officer job characteristics. One item asked respondents to specify their division. Based on regression requirements, we compiled a binary dummy variable from this item specifying uniformed and non-uniformed divisions. The second item asked respondents to specify their rank (constable to superintendent and above). The third job characteristics item asked respondents to specify their length of tenure. Both of these variables were entered as ordinal items in the regression models.

\section{Personal characteristics}

Eight items in the survey elicited personal characteristics data. Respondents were asked to specify their sexual orientation. Due to low numbers in the bisexual categories and the requirements of H3, a dummy variable was compiled for the regression models which compared Gay men against all other categories. A similar procedure was used on the ethnicity item to derive a binary BME variable. The next item asked respondents to whom they had openly disclosed their sexual orientation (friends and family). A scale variable was computed using this data which was entered into the regression models as a continuous predictor. The remainder of the personal characteristics items [out at work, Gay Police Association (GPA) and local force LGB staff network member] were entered into the models as binary variables. Age of officer was entered as a continuous predictor. 


\section{Results}

Univariate statistics and description of the LGB officer sample

Table 1 details univariate and descriptive statistics of respondents. The sample consisted of 836 LGB police officers from the 43 forces in England and Wales. There was roughly equal representation from small, medium and large forces. Of the respondents, nearly one-fifth were non-uniformed and the majority had between 1 and 10 years of service. The rank profile of the sample matched the PSS statistics for England and Wales (Dhani 2012), with just over three quarters of respondents reporting Constable rank (see Table 2). A large proportion of the sample identified as lesbian or gay woman (just under half), followed by gay man $(38 \%)$, bisexual man $(9 \%)$ and bisexual woman (7\%). Five per cent of the sample identified as Black Minority Ethnic, which mirrors the figures for PSS in England and Wales (Dhani 2012). Over three quarters of the sample had disclosed their sexual orientation to colleagues at work, with just under one-third reporting membership to the GPA and just under half reporting membership to their local force LGB staff network. Female respondents were over-represented in the sample compared to PSS statistics. This is likely due to the topic of the survey and the willingness of LGB women to come forward to reveal their occupational experiences. We acknowledge that this oversampling may skew the results reported later in the paper, particularly in relation to intersectionality (in this case gender intersecting with sexual orientation). Given the cross-sectional nature of this research, it is not possible to indicate with a high degree of certainty whether it is sexual orientation or gender that accounts for the experiences reported. However, given respondents were asked about discrimination based on sexual orientation and not gender in the survey, we can tentatively conclude any significant findings that do emerge are attributable to perceptions of this type of discrimination. Nonetheless, a note of caution is necessary when interpreting these results to the wider police personnel population.

\section{Bivariate statistics}

Table 1 also details the results from the bivariate analysis of experience of discrimination in training, deployment and promotion. Overall $17 \%$ of the sample perceived had been a victim of discrimination in the workplace. Less than a quarter of victims $(24 \%)$ officially reported their discrimination. The largest area for discrimination was deployment (10\%) followed by training $(9 \%)$ and promotion $(4 \%)$. Statistical differences emerged in relation to force type for the area of promotion where LGB officers in large forces reported experiencing higher levels of discrimination compared to medium-sized forces. Not surprisingly, length of tenure and rank emerged as highly significant, with those serving for longer periods of time and those of higher rank more likely to have experienced all types of discrimination. Similarly, older LGB officers were more likely to have experienced discrimination in training and deployment. A significant difference emerged in perceived discrimination in deployment and promotion between gay men and all other sexual orientation types, with the former reporting more experience. BME LGB respondents were also significantly more likely to report perceived discrimination in training and deployment, compared to their White counterparts. A significant difference also emerged between those out at work and not, with the former more likely to report 
Table 1. Descriptive and bivariate statistics $(N=836)$.

\begin{tabular}{|c|c|c|c|c|c|c|c|c|c|}
\hline & \multirow[b]{2}{*}{ Coding } & \multicolumn{2}{|c|}{ Sample } & \multicolumn{2}{|c|}{$\begin{array}{l}\text { Discrimination in } \\
\text { training }\end{array}$} & \multicolumn{2}{|c|}{$\begin{array}{c}\text { Discrimination in } \\
\text { deployment }\end{array}$} & \multicolumn{2}{|c|}{$\begin{array}{l}\text { Discrimination in } \\
\text { promotion }\end{array}$} \\
\hline & & $M$ & $\mathrm{SD}$ & $\%$ & $\chi^{2} / \beta(\mathrm{df})$ & $\%$ & $\chi^{2} / \beta(\mathrm{df})$ & $\%$ & $\chi^{2} / \beta(\mathrm{df})$ \\
\hline \multicolumn{10}{|l|}{ Dependent variable } \\
\hline \multicolumn{9}{|l|}{ Independent variables } & \\
\hline \multirow[t]{3}{*}{ Force size } & $1=$ Small & 0.30 & 0.46 & 8.8 & $1.76(2)$ & 9.2 & $3.66(2)$ & 4.2 & $7.58(2)^{* *}$ \\
\hline & $2=$ Medium & 0.36 & 0.48 & 6.8 & & 8.6 & & 2.1 & \\
\hline & $3=$ Large & 0.34 & 0.47 & 9.9 & & 13.1 & & 6.7 & \\
\hline \multirow[t]{2}{*}{ Uniform } & $0=$ Non-uniformed & 0.18 & 0.39 & 12.5 & $3.77(1)^{*}$ & 9.9 & $0.04(1)$ & 2.6 & $1.28(1)$ \\
\hline & $1=$ Uniformed & 0.82 & 0.36 & 7.6 & & 10.4 & & 4.7 & \\
\hline \multirow[t]{5}{*}{ Length of tenure } & $1=1-5$ years & 0.32 & 0.47 & 4.1 & $10.99(4)^{* *}$ & 5.6 & $13.51(4)^{* * *}$ & 1.1 & $21.74(4)^{* * *}$ \\
\hline & $2=6-10$ years & 0.32 & 0.47 & 11.5 & & 10.7 & & 4.8 & \\
\hline & $3=11-15$ years & 0.13 & 0.34 & 10.2 & & 14.8 & & 1.9 & \\
\hline & $4=16-20$ years & 0.11 & 0.31 & 7.5 & & 17.2 & & 7.9 & \\
\hline & $5=21$ years and above & 0.12 & 0.32 & 11.1 & & 10.1 & & 11.1 & \\
\hline \multirow[t]{4}{*}{ Rank } & $1=$ Constable & 0.76 & 0.43 & 7.1 & $9.98(3)^{* *}$ & 8.2 & $24.67(3)^{* * *}$ & 2.0 & $49.22(3) * * *$ \\
\hline & $2=$ Sergeant & 0.16 & 0.36 & 13.8 & & 15.4 & & 8.5 & \\
\hline & $3=$ Inspector $/$ chief & 0.06 & 0.23 & 15.6 & & 28.9 & & 22.2 & \\
\hline & $4=$ Superintendent and above & 0.03 & 0.17 & 4.0 & & 4.0 & & 8.0 & \\
\hline \multirow[t]{4}{*}{ Sexual orientation } & $1=$ Gay man & 0.38 & 0.49 & 11.0 & $7.26(3)^{*}$ & 13.5 & $13.91(3)^{* * *}$ & 6.9 & $9.11(3)^{* *}$ \\
\hline & $2=$ Gay woman & 0.46 & 0.50 & 8.2 & & 10.6 & & 3.2 & \\
\hline & $3=$ Bisexual Man & 0.09 & 0.28 & 5.1 & & 3.8 & & 1.3 & \\
\hline & $4=$ Bisexual woman & 0.07 & 0.25 & 1.7 & & 0.0 & & 1.7 & \\
\hline \multirow[t]{2}{*}{ In a relationship } & $0=\mathrm{No}_{\mathrm{O}}$ & 0.24 & 0.43 & 7.3 & $0.49(1)$ & 9.8 & $0.08(1)$ & 5.4 & $0.73(1)$ \\
\hline & $1=$ Yes & 0.76 & 0.42 & 8.9 & & 10.5 & & 4.0 & \\
\hline Age & & 36.20 & 8.10 & & $0.04(1)^{* * *}$ & & $0.02(1)$ & & $0.06(1)^{* * *}$ \\
\hline \multirow[t]{2}{*}{ Ethnicity } & $0=$ White & 0.95 & 0.21 & 7.9 & $7.20(1)^{* * *}$ & 9.8 & $4.33(1)^{* *}$ & 4.1 & $1.05(1)$ \\
\hline & $1=\mathrm{BME}$ & 0.05 & 0.21 & 20.0 & & 20.0 & & 7.5 & \\
\hline
\end{tabular}


Table 1 (Continued)

\begin{tabular}{|c|c|c|c|c|c|c|c|c|c|}
\hline & \multirow[b]{2}{*}{ Coding } & \multicolumn{2}{|c|}{ Sample } & \multicolumn{2}{|c|}{$\begin{array}{l}\text { Discrimination in } \\
\text { training }\end{array}$} & \multicolumn{2}{|c|}{$\begin{array}{l}\text { Discrimination in } \\
\text { deployment }\end{array}$} & \multicolumn{2}{|c|}{$\begin{array}{l}\text { Discrimination in } \\
\text { promotion }\end{array}$} \\
\hline & & $M$ & $\mathrm{SD}$ & $\%$ & $\chi^{2} / \beta(\mathrm{df})$ & $\%$ & $\chi^{2} / \beta(\mathrm{df})$ & $\%$ & $\chi^{2} / \beta(\mathrm{df})$ \\
\hline \multirow[t]{2}{*}{ Out at work } & $0=\mathrm{No}$ & 0.21 & 0.41 & 5.2 & $3.25(1)^{*}$ & 6.4 & $3.90(1)^{* *}$ & 3.5 & $0.42(1)$ \\
\hline & $1=$ Yes & 0.79 & 0.40 & 9.6 & & 11.6 & & 4.6 & \\
\hline Out to family/friends (scale) & Range $=0-6$ & 4.68 & 1.79 & & $0.12(1)$ & & $0.15(1)^{* *}$ & & $0.12(1)$ \\
\hline \multirow{2}{*}{ GPA member } & $0=\mathrm{No}$ & 0.70 & 0.46 & 7.0 & $5.94(1)^{* *}$ & 8.8 & $5.64(1)^{* *}$ & 3.4 & $3.97(1)^{* *}$ \\
\hline & $1=$ Yes & 0.30 & 0.46 & 12.2 & & 14.3 & & 6.5 & \\
\hline \multirow[t]{2}{*}{ Force LGB group member } & $0=\mathrm{No}$ & 0.54 & 0.50 & 6.9 & $3.08(1)^{*}$ & 9.5 & $1.39(1)$ & 3.0 & $2.50(1)$ \\
\hline & $1=$ Yes & 0.46 & 0.50 & 10.4 & & 12.1 & & 5.2 & \\
\hline
\end{tabular}

Valid percentages reported.

${ }^{*} p \leq 0.10 ;{ }^{* *} p \leq 0.05 ; * * * p<0.01$ 
Table 2. Sample compared to Police Service Strength (PSS) on 30 March 2012.

\begin{tabular}{|c|c|c|c|c|}
\hline & \multicolumn{2}{|c|}{$\begin{array}{l}\text { LGB officer } \\
\text { sample }\end{array}$} & \multicolumn{2}{|c|}{ PSS 2012} \\
\hline & $N$ & $\%$ & $N$ & $\%$ \\
\hline \multicolumn{5}{|l|}{$\operatorname{Rank}^{\mathrm{a}}$} \\
\hline Constable & 636 & 75.9 & 105,068 & 77.0 \\
\hline Sergeant & 130 & 15.5 & 21,623 & 15.8 \\
\hline Inspector/chief & 45 & 5.4 & 8357 & 6.1 \\
\hline Superintendent and above & 25 & 2.5 & 1481 & 1.1 \\
\hline \multicolumn{5}{|l|}{ Race $^{\mathrm{b}}$} \\
\hline White & 798 & 95.2 & 127,437 & 95.0 \\
\hline BME & 40 & 4.8 & 6664 & 5.0 \\
\hline \multicolumn{5}{|l|}{ Gender $^{\mathrm{b}}$} \\
\hline Male & 400 & 47.8 & 98,139 & 73.2 \\
\hline Female & 437 & 52.1 & 35,962 & 26.8 \\
\hline
\end{tabular}

Notes: Valid percentages reported.

${ }^{a}$ Rank PSS figures based on all staff headcount.

${ }^{\mathrm{b}}$ Race and gender PSS figures based on Full-Time Equivalent.

perceived discrimination in deployment. Members of the GPA were also more likely to experience discrimination across all types, compared to non-members. All variables in the bivariate analysis were included in the multivariate models in order to identify which variables or set of variables were able to best predict the likelihood of experiencing discrimination, while controlling for various factors such as length of tenure.

\section{Methods of estimation}

Three logistic regression models were fit to the experience of discriminationdependent variables (training, deployment and promotion). This is the most appropriate type of regression for binary responses (Yes/No). Model diagnostics indicated a robust fit to the data in each case (see Table 3). A fourth dependent variable measured how many types of discrimination officers experienced in their career to the date of the survey. As this variable was best described as a count measure, with the majority not experiencing any discrimination types, and a minority experiencing one or more types, a ZIP regression model was used to fit to the data using the statistical program $\mathrm{R}$. There exists a growing methodological and empirical literature on regression models for count data (see Land et al. 1996, Zorn 1998, Robinson 2003). Count variables represent types of events that are largely not experienced by the majority of the sample (in our case discrimination in the workplace). Linear regression models are not appropriate for count variables given the non-linear distribution of the data (Land et al. 1996). Poisson-related models are suited to this kind of data as they are built on assumptions about error distributions that are consistent with the nature of event counts (Cameron and Trivedi 1998).

Cameron and Trivedi (1998) note Poisson regression assumes that the mean and the variance of the outcome measure are equal (or close to equal). Over-dispersion of count data was suspected in our outcome variable (mean $=0.26$ and variance $=$ 
0.44). While these diagnostics may not prove a cause for significant concern, a zeroinflated Negative Binomial (ZINB) regression model was fit to the data as a comparison to the ZIP (ZINB regression accounts for over-dispersion which may be responsible for a poor fitting model). The dispersion parameter $\log ($ theta) of the ZINB model was not significantly different from zero (p 0.85). ${ }^{4}$ This suggests that our outcome variable was not over-dispersed and that a ZIP model was more appropriate than a ZINB model.

Zero-inflated models are appropriate for data where there may be an excessive amount of zeros ( $83 \%$ in this case of our count of discrimination outcome variable). The assumption behind such models is that excess zeros are generated by a separate process from the count values and that they can be modelled independently in a binomial inflation model. We assumed that the variable 'being out at work' may impact upon the exposure to discriminatory acts in the workplace, where not being out at work may account for a reduced likelihood of discrimination (given a reduced exposure to discriminators) and hence excessive zeros in the count outcome measure. A Vuong test which compares the ZIP model versus the standard Poisson model (likelihood ratio test of alpha $=0$ ) was conducted. The test suggested that the ZIP model was a significant improvement over a standard Poisson model $(p<0.01)$.

As the rate of discrimination varies by the amount of exposure to situations in which these acts may manifest, an exposure variable was entered into the ZIP equation. This was done by including the length of tenure measure as the offset variable in R. By defining the offset variable, the equation adjusts for the amount of opportunity a discriminatory event has. The assumption is that an increase in tenure is associated with an increased chance of discrimination. An LGB officer with more than 10 years of tenure is more likely to have been exposed to more opportunities for discrimination and experienced such acts, as compared to an LGB officer with less than 5 years of tenure.

Finally, we compared the ZIP model to a null model without predictors using chisquared test on the difference of log-likelihoods. The ZIP model predicting counts of discrimination types was statistically significant $\left(x^{2}=20.40\right.$, degree of freedom $[\mathrm{df}]=$ $14, \mathrm{p}<0.001$ ). The predictors of excess zeros (out at work and length of tenure) were statistically significant. Results in all models run (Poisson, ZIP and ZINB) were very similar indicating the inferences made later in the paper were unaffected by model choice. Results from correlational analyses, and tolerance statistics and varianceinflation factors showed that there were no problems with multicollinearity among the independent variables. $^{5}$

\section{Model results}

Three sets of predictor variables (force, job and personal characteristics) were regressed onto the binary discrimination variables (training, deployment and promotion) using logistic regression (Table 3) and the count of types of discrimination variables using Poisson regression (Table 4).

\section{Force characteristics}

Holding all other factors constant, significant associations emerged in relation to force characteristics and perceived work-based discrimination. Small force size was 
Table 3. Logistic regression predicting discrimination.

\begin{tabular}{|c|c|c|c|c|c|c|c|c|c|c|c|c|}
\hline & \multicolumn{4}{|c|}{ Training } & \multicolumn{4}{|c|}{ Deployment } & \multicolumn{4}{|c|}{ Promotion } \\
\hline & $\beta$ & SE & Wald & $\operatorname{Exp}(\beta)$ & $\beta$ & $\mathrm{SE}$ & Wald & $\operatorname{Exp}(\beta)$ & $\beta$ & SE & Wald & $\operatorname{Exp}(\beta)$ \\
\hline \multicolumn{13}{|l|}{ Force characteristics } \\
\hline Small & 1.28 & 0.51 & 6.27 & $3.59 * *$ & 0.40 & 0.41 & 0.92 & 1.49 & 0.62 & 0.97 & 0.41 & 1.86 \\
\hline $\begin{array}{l}\text { Large } \\
\text { Pef. medium) }\end{array}$ & 1.02 & 0.55 & 3.43 & $2.76^{*}$ & 0.95 & 0.39 & 5.85 & $2.58^{* *}$ & 1.57 & 0.91 & 2.97 & $4.80^{*}$ \\
\hline \multicolumn{13}{|l|}{ (Ref: medium) } \\
\hline Uniformed & -1.48 & 0.41 & 13.39 & $0.23^{* * *}$ & 0.17 & 0.39 & 0.19 & 1.19 & 1.41 & 1.18 & 1.42 & 4.10 \\
\hline Length of tenure & -0.22 & 0.20 & 1.18 & 0.81 & 0.32 & 0.18 & 3.12 & $1.37^{*}$ & 0.77 & .44 & 3.04 & $2.16^{*}$ \\
\hline Rank & 0.33 & 0.25 & 1.74 & 1.39 & 0.43 & 0.19 & 5.36 & $1.54^{* *}$ & 0.96 & 0.30 & 9.92 & $2.61 * * *$ \\
\hline \multicolumn{13}{|l|}{ Personal characteristics } \\
\hline Gay man & 1.03 & 0.41 & 6.26 & $2.80^{* *}$ & 0.72 & 0.31 & 5.26 & $2.05^{* *}$ & 2.18 & 0.76 & 8.28 & $8.83^{* * *}$ \\
\hline In a relationship & 0.27 & 0.49 & 0.30 & 1.31 & -0.11 & 0.36 & 0.10 & 0.90 & -0.38 & 0.89 & 0.18 & 0.68 \\
\hline Age & 0.11 & 0.03 & 10.91 & $1.12 * * *$ & 0.00 & 0.03 & 0.02 & 1.00 & 0.03 & 0.08 & 0.19 & 1.03 \\
\hline BME & 2.36 & 0.60 & 15.46 & $10.54 * * *$ & 1.82 & 0.52 & 12.14 & $6.20 * * *$ & 1.25 & 1.10 & 1.30 & 3.49 \\
\hline Out at work & 2.24 & 0.87 & 6.58 & $9.42 * *$ & 0.72 & 0.63 & 1.33 & 2.06 & 0.97 & 1.19 & 0.67 & 2.63 \\
\hline Out to family/friends (scale) & -0.32 & 0.15 & 4.38 & $0.73^{* *}$ & 0.17 & 0.13 & 1.58 & 1.19 & -0.10 & 0.26 & 0.16 & 0.90 \\
\hline GPA member & 0.89 & 0.44 & 4.06 & $2.43^{* *}$ & 0.87 & 0.34 & 6.60 & $2.39 * *$ & -0.52 & 0.78 & 0.45 & 0.59 \\
\hline Force LGB group member & 0.31 & 0.47 & 0.43 & 1.36 & -0.06 & 0.35 & 0.03 & 0.94 & 0.02 & 0.76 & 0.00 & 1.02 \\
\hline Constant & -8.72 & 1.50 & 33.85 & & -6.65 & 1.21 & 30.21 & & -13.10 & 3.33 & 15.51 & \\
\hline \multicolumn{13}{|l|}{ Model fit } \\
\hline$-2 \log$ likelihood & & 231.369 & & & & 355.698 & & & & 87.231 & & \\
\hline $\mathrm{df}$ & & 8 & & & & 8 & & & & 8 & & \\
\hline sig. & & 0.000 & & & & 0.000 & & & & 0.000 & & \\
\hline$N^{\mathrm{a}}=$ & & 755 & & & & 760 & & & & 766 & & \\
\hline Nagelkerke pseudo $R^{2}$ & & 0.286 & & & & 0.203 & & & & 0.400 & & \\
\hline Percentage classified correctly & & 94.8 & & & & 91.6 & & & & 98.3 & & \\
\hline
\end{tabular}

${ }^{a}$ Reduction in sample size due to list-wise deletion of cases necessary for regression requirements.

${ }^{*} p<0.10 ;{ }^{* *} p<0.05 ;{ }^{* * *} p<0.01$. 
significantly positively associated with perceived experience of discrimination in training. Log-odds ratios indicated that LGB officers from these forces were over three and a half times more likely to experience discrimination in this part of the job compared to the reference category (medium-sized forces). Large force size was significantly positively associated with perceived experience of discrimination in deployment, but the model results for this variable only approached conventional levels of significance in training and promotion. LGB officers in large forces were over two and a half times more likely than those in medium-sized forces to experience discrimination in deployment.

\section{Job characteristics}

Job characteristics emerged as significant in all the three models. Holding all other factors constant, being of senior rank was predictive of perceived discrimination in both deployment and promotion. In terms of the former, senior officers were one and a half times more likely to experience discrimination, and in the latter were over two and a half times more likely. Length of tenure was positively associated with discrimination in deployment and training, but only approached conventional levels of significance, indicating that rank is the stronger predictor of the two variables. Being non-uniform was positively associated with perceived discrimination in training only. Log-odds ratios show that non-uniformed officers were near four and a half times more likely to report experiences of discrimination in this part of the job compared to uniformed officers.

\section{Personal characteristics}

Both gay man and BME variables were the strongest predictors of all personal characteristics. Holding all other factors constant, significant positive associations emerged between gay male officer and perceived experience of discrimination in training, deployment and promotion. Compared to all other minority sexual orientations, gay male officers were nearly three times as likely to experience discrimination in training, just over twice as likely in deployment and near nine times as likely in promotion. Compared to LGB white officers, LGB BME officers were over 10 times as likely to perceive experience of discrimination in training, and just over six times as likely to perceive experience of discrimination in deployment. Significant positive associations also emerged between being out at work and being a GPA member and perceiving discrimination. Log-odds ratios show that being out at work increases the likelihood of discrimination in training by a factor of just shy of ten. Correspondingly being less out to family and friends was positively associated with not being discriminated against training. A positive association between being a member of the GPA and discrimination in training and deployment was also present.

\section{Sub-model analysis}

In order to determine which set of variables (force, job or personal characteristics) were most predictive of discrimination, sub-model analysis was conducted. Comparing the -2 log-likelihoods and pseudo R-squared value of each sub-model allowed for the determination of which set of independent variables explained the 
most variance in the dependent variables. For all types of discrimination the personal characteristics set of variables emerged as most predictive, explaining $7 \%$ of the variance in the dependent in relation to training, $6 \%$ in relation to deployment and $11 \%$ in relation to promotion. The Job Characteristics set of variables also explained $11 \%$ of the variance in the dependent variable for promotion, demonstrating discrimination in this area is best predicted by these variables as well as personal characteristics.

\section{Counts of types of discrimination}

The Poisson model predicting counts of types of discrimination (Table 4) showed significant positive associations in relation to all sets of predictor variables (force, job and personal characteristics). Holding all other factors constant, the large-sized police services variable was predictive of experiencing more than one type of discrimination (training/deployment/promotion). LGB officers in these forces were

Table 4. Zero-inflated Poisson regression predicting count of discrimination types.

\begin{tabular}{|c|c|c|c|}
\hline \multirow[b]{2}{*}{ Poisson model (count/true zeros) } & \multicolumn{3}{|c|}{ Count of discrimination types } \\
\hline & Coefficient & SE & $Z$ \\
\hline \multicolumn{4}{|l|}{ Force characteristics } \\
\hline Small & 0.22 & 0.21 & 1.02 \\
\hline $\begin{array}{l}\text { Large } \\
\text { (Ref: medium) }\end{array}$ & $0.55 * * *$ & 0.21 & 2.60 \\
\hline \multicolumn{4}{|l|}{ Job characteristics } \\
\hline Uniformed & 0.05 & 0.21 & 0.26 \\
\hline Rank & 0.06 & 0.10 & 0.54 \\
\hline \multicolumn{4}{|l|}{ Personal characteristics } \\
\hline Gay man & $0.45^{* *}$ & 0.18 & 2.56 \\
\hline In a relationship & -0.12 & 0.21 & -0.56 \\
\hline Age & 0.00 & 0.01 & 0.22 \\
\hline $\mathrm{BME}$ & $0.77 * * *$ & 0.45 & 1.70 \\
\hline Out to family/friends (scale) & -0.08 & 0.09 & 0.06 \\
\hline GPA member & 0.03 & 0.19 & 0.13 \\
\hline Force LGB group member & 0.19 & 0.20 & 0.95 \\
\hline Length of tenure & (exposure) & & \\
\hline Constant & -1.83 & 0.66 & -2.76 \\
\hline \multicolumn{4}{|c|}{ Binomial model (inflation/excess zeros) } \\
\hline Out at work & $-0.86^{* *}$ & 0.40 & -2.19 \\
\hline Constant & 1.96 & 0.46 & 4.21 \\
\hline \multicolumn{4}{|l|}{ Model fit } \\
\hline Log-L & -480.25 & & \\
\hline Chi-square & 29.40 & & \\
\hline $\mathrm{df}$ & 14 & & \\
\hline Significance & .000 & & \\
\hline Vuong & -2.74 & & \\
\hline $\mathrm{N}^{\mathrm{a}}=$ & 770 & & \\
\hline
\end{tabular}

${ }^{\mathrm{a}} N=770$ (Reduction in sample size due to listwise deletion of cases necessary for regression requirements). ${ }^{*} p<0.10 ;{ }^{* *} p<0.05 ; * * * p \leq 0.01$. 
significantly more likely to experience more than one type of discrimination compared to medium-sized forces. Both gay male and BME variables were also positively associated with the counts of discrimination. Gay male and BME officers were significantly more likely to suffer more than one type of discrimination. Unlike the logistic models, rank did not emerge as predictive of experiencing more than one type of discrimination. This may be related to the inclusion of the offset variable (length of tenure) which adjusts for exposure to discrimination over time, accounting for the higher levels experienced by more senior officers. The predictor of excess zeros (out at work) was also statistically significant. Being out at work decreased the logodds of membership to the excess zero-generating process by 0.86 . Conversely, not disclosing an LGB identity at work increased the likelihood belonging to the excess zero category, confirming our assumption that officers who are not out may be 'immune' from homophobic discrimination (an alternative zero-generating process). ${ }^{6}$

\section{Discussion}

All four of our hypotheses were broadly supported by the data. Based on research that evidences discrimination varies by force characteristics (Fyfe 1991, Neal 2002, Holloway 2005, Yarwood and Mawby 2010), we postulated that perceived experience of discrimination across all types (training, deployment and promotion) would vary by force size. Our analysis suggests that size of force is a statistically influential factor in the prediction of discrimination in two of the three employment areas identified in the survey: training and deployment. In particular, compared to medium-sized forces, LGB officers in smaller and larger forces were more likely to perceive discrimination in training and deployment, respectively. In an attempt to understand the association of discrimination in training in relation to smaller forces, we draw upon the work of Neal (2002), Holloway (2005) and Yarwood and Mawby (2010) which shows how several factors explain exposure to discriminatory practices in small rural settings, including community makeup, exposure to diversity and human resource demographics. Holloway identifies the 'resistance to otherness' in rural settings as a possible contributory factor in the formation of negative and stereotypical attitudes toward LGB officers. It is possible that such factors are responsible for discrimination in training in small forces in our study. However, why discrimination is more likely in training and not promotion and deployment in these smaller forces is a question that requires further qualitative empirical investigation. Furthermore, we acknowledge that not all small forces in our study were rural (and that not all large were urban). Unfortunately, the survey did not ask respondents to specify if they were based in rural, urban or mixed environments. Therefore, the work cited above that focuses on rural forces can only be applied to the patterns of perceived discrimination identified in this study in a tentative fashion.

The statistical association of discrimination in deployment with large forces replicates Burke's (1993) findings. Furthermore, the Poisson model predicting counts of discrimination revealed that those in large forces were significantly more likely to experience all three forms of discrimination compared to medium and small forces. Twenty years on, it seems that discrimination against LGB officers in large forces has not been eradicated. In attempting to explain discrimination in deployment (and to some extent promotion, although this association only approached conventional levels of significance), but not training in large forces, we draw on Colvin (2008) who 
found that instances of discrimination occurred in areas where supervisory discretion is highest: annual evaluations, workload allocation and support for promotion and development. A lack of supervisory discretion in training therefore may explain a lack of association with perceived discrimination. It is interesting however to note that while supervisory discretion is still undoubtedly prevalent in small and medium forces, our data does not suggest the areas where it is likely to be exercised (deployment and promotion) result in perceived homophobic discrimination in these forces. This may be partly explained by the Poisson model that shows homophobic discrimination is more likely to occur across all employment areas in large forces (which may seem counter-intuitive and in contradiction to existing research which indicates that smaller forces are associated with higher levels of discrimination of various types). Again, to explain this seemingly counter-intuitive pattern, we would suggest that further qualitative work is needed. Overall the force characteristics variable explained the least amount of discrimination compared to job and personal characteristics, evidencing that while size of force is associated with negative experiences, it is the weakest predictor and hence potentially the least important in terms of policy recommendations.

Based on research that suggests the experience of women and BME officers across ranks and divisions is not homogeneous (Bland et al. 1999, Brown and Heidensohn 2000), our second hypothesis postulated that perceived experience of LGB discrimination would vary by the job characteristics of rank and uniformed/ non-uniformed. Senior rank emerged as predictive of perceived discrimination in relation to both deployment and promotion, while being non-uniformed was predictive of perceived discrimination in training only. Given that length of tenure also formed part of the models, we can be confident that being of greater risk from discrimination in these areas because higher rank is not due to the increased amount of exposure (in time) to discrimination opportunities. This is further confirmed by the absence of multicollinearity between the length of tenure and rank variables (i.e. they were unrelated in terms of their association with discrimination). ${ }^{7}$ Therefore, there is something about the experience of being of higher rank, apart from length of tenure that increases LGB officers' chances of discrimination in deployment and promotion. It may be the case that officers of higher rank expose themselves to discrimination simply by virtue of entering the application process. Those who have less ambition to expand their policing portfolio or rise the ranks reduce their chances of discrimination by avoiding this application process. Furthermore, the statistical association between non-uniformed [e.g. Criminal Investigation Department (CID)] and perceived discrimination in training supports the above line of reasoning. Training related to non-uniformed positions in the police is likely to occur in relation to deployment (e.g. to CID) and/or promotion, further corroborating the argument that 'experiencing' deployment and promotion (in this case via specialist training) results in a higher likelihood of perceiving discrimination. These findings resonate with those of Praat and Tuffin (1996) who found discriminatory practices in relation to deployment in a New Zealand police service. We postulate, like Colvin (2008) that high supervisory discretion in the areas of deployment and promotion is likely to partly explain higher chances of discrimination. Furthermore, job characteristics variables as a set were highly predictive of perceived discrimination in promotion, equal to personal characteristics, indicating that they are important in relation to policy development (see Conclusion section). 
Based on evidence that demonstrates experience of homophobic discrimination varies between sexual orientation types (Williams and Robinson 2004, 2007, Stonewall 2008), our third hypothesis postulated that gay male officers would be significantly more likely to experience discrimination in their occupational role compared to gay female, bisexual female and bisexual male officers. Being a gay male police officer was strongly associated with discrimination in all three employment areas independently (as indicated in the logistic models) and in combination (as indicated in the Poisson model). Praat and Tuffin argue that the heterosexual stereotypical imaginings of gay men are responsible for this clear pattern of discrimination. They argue that gay males are often associated with femininity and that this discursive construction 'may be used to construct a type or types of homosexuals who may be subsequently rejected as candidates for policing' (1996, p. 70). Such rejection manifests itself at various stages of employment, including training, deployment and promotion. Furthermore, like Praat and Tuffin, Burke (1993) argues that, in contrast to gay women and bisexuals, the marred history between the police and the gay men, from the times of criminalisation and the policing of vice, remains ossified in the cultural fabric of the institution, reproducing discrimination in day-to-day experiences on the job. This pattern of disproportionate discrimination of gay men is replicated in almost all other studies on the topic in the $\mathrm{UK}$ and beyond.

Our final hypothesis postulated that officers with multiple minority identities (in our case BME LGB officers) would be more likely to experience each type of discrimination in isolation and in combination. In relation to the former, our analysis suggests that these officers were highly statistically more likely to experience discrimination compared to non-BME LGB officers in relation to training and deployment, but not promotion. The BME variable was by far the most influential in the models, indicating the importance of ethnicity in predicting discrimination of this nature. In relation to the latter, the Poisson model showed that the BME variable was the most significant in predicting multiple discrimination across the three types. The stark differences between BME and non-BME LGB officers in relation to perceived discrimination are mirrored in other research, including the Gay British Crime Survey (Stonewall 2008). This survey showed that compared to non-BME LGB respondents, BME LGB respondents were twice as likely to report a physical homophobic hate incident, three and a half times more likely to report unwanted sexual contact, and over one and a half times more likely to think there is a hate crime problem in their local area. Williams and Robinson $(2004,2007)$ showed broadly similar results in their research based on the Welsh LGB population. Evidence from this study indicates that this pattern of double discrimination persists in relation to employment in policing. The lack of a significant association between BME LGB officer status and discrimination in promotion was surprising, given the Home Office research by Bland et al. (1999) that found BME officers on average took 12 months longer than their White counterparts to reach the rank of sergeant, and 16-23 months longer to reach Inspector, despite only a slight difference in the average time to first attempt promotion. Our findings suggest that this pattern might not extend to LGB BME officers; or possibly that these respondents in our study did not perceive a delay in promotion as a result of homophobic discrimination. However, as observed by Loftus (2009) where an officer possesses intersectional identities, it is often unclear which of their identity characteristics (i.e. gender, 
sexuality and/or ethnicity) are the target of discriminatory experiences. Accordingly, the complexities of intersectionality in policing are another topic that requires qualitative exploration. Overall, the personal characteristics set of variables were the most predictive of perceived discrimination across the board, indicating their central importance in policy change and development.

\section{Conclusions}

Twenty years ago Mark Burke's (1993, 1994) research evidenced widespread prejudice and hostility toward gay male police officers in forces across England and Wales. Respondents reported adverse treatment during the recruitment process, psychologically damaging experiences during training, unfair allocation of duties and bars to promotion and development. Twenty years on this research, which represents the largest survey at date of publication of LGB police officers in England and Wales, evidences that just under one-fifth reported experiencing discrimination, with those in small and large forces, those in senior ranks and non-uniformed positions, and those who identify as gay male and BME experiencing the highest levels of victimisation. However, it would be misleading to not acknowledge the improvements that have been made in relation to the employment of LGB officers. Like Belkin and McNichol (2002), we recognise the considerable improvements in police working environments for minority officers, brought about by the pursual of a new police organisational morality. Yet, despite this, instances of homophobic discrimination in training, deployment and promotion are still evident in British policing. The roots of this discrimination are likely to be complex and are beyond the scope of this study. However, as a starting point, we would postulate like Ward (2007) that sexuality is a social construction and as such it is difficult to determine the aetiology of discriminatory attitudes and behaviours. This is partly due to overlap and positioning of individuals within sites of social reproduction. Accordingly, as long as the wider 'conservative' masses in society express prejudice against LGB individuals and groups, then prejudice is likely to exist within the police organisation. Ward concludes that just as race and gender anti-discrimination policy has had a limited impact so it is likely that cognate LGB policies will encounter the same fate. We do not take such a bleak view and suggest that our research has several implications for local force and national policy in relation to LGB diversity in policing. We argue that our findings suggest like Colvin's (2008), there is a need for a reduction in supervisory discretion in certain contexts, especially in relation to deployment and promotion, including associated specialist training. We would also recommend a policy focus on supporting gay male officers and BME LGB officers in all employment areas. Furthermore, like Brown and Woolfenden (2011), we support the position that a central aim of the diversity reform agenda must be a renegotiation of the psychological contract between the staff and the organisation. The organisation must aim to avoid a transactional relationship "a purely economic exchange of money for labour with no personal investment. Instead a relational setup must be sought" where mutual expectations of exchange are established and efforts are made to create a rich working environment that draws upon and invests in the subjective and intersubjective identity characteristics of LGB police officers. Despite acknowledging considerable improvements in the workplace experiences of LGB police officers today, we conclude that moral organisational efforts that have brought about these 
changes should not be seen as complete but rather as a commendable and effective portfolio of initiatives that should continue to capture police organisational attention and investment in order to sustain and further improve the working climates of LGB police officers.

\section{Acknowledgements}

This work is based on the project "Cultures of Difference: Exploring the Workplace Complexities Faced by Lesbian, Gay and Bisexual Police Officers across England and Wales", that was funded by the Economic and Social Research Council (Grant Reference: ES/ G010765/1).

\section{Notes}

1. Force size is included as a proxy for urban, semi-urban and rural forces. We acknowledge that there are limitations using size as a proxy for cosmopolitan versus parochial distinctions but proceeded with this option, given the issues associated with officers subjectively classifying their own policing environment and the high likelihood of resulting missing data. Home Office police service strength statistics (31 March 2012) were used to derive size categories. Small force=less than 1500 officers, medium size force $=1501-3000$ officers and large force $=$ more than 3001 officers.

2. See http://www.survey.bris.ac.uk/.

3. See https://aoir.org/documents/ethics-guide/.

4. Note that R parameterises this differently from SAS and Stata. The R parameter (theta) is equal to the inverse of the dispersion parameter (alpha) estimated in these other software packages (see http://www.ats.ucla.edu/stat/r/dae/nbreg.htm).

5. Results from negative binomial regression and multicollinearity diagnostics are not shown but are available upon request. Pseudo $\mathrm{R}^{2}$ statistics are presented in Table 3 .

6. Accepting that suspicion of a same-sex sexual preference and association with LGB individuals can also result in homophobic discrimination.

7. Although this may not be the case in the Poisson model where we predicted cumulative discrimination and included length of tenure as the offset variable and rank did not emerge as significant.

\section{References}

Bernstein, M. and Kostelac, C., 2002. Lavender and blue: attitudes about homosexuality and behaviour toward lesbians and gay men among police officers. Journal of Contemporary Criminal Justice, 18 (3), 302-328.

Belkin, A. and McNichol, J., 2002. Pink and blue: outcomes associated with the integration of open gay and lesbian personnel in the San Diego Police Department. Police Quarterly, 5 (1), 63-95.

Bland, N., et al., 1999. Career progression of ethnic minority police officers. Police research series article, 107: Home Office, Research, Development and Statistics Directorate. London: Home Office.

Brown, J., 2007. From cult of masculinity to smart macho: gender perspectives on police occupational culture. In: M. O'Neill, M. Marks, and A.-M. Singh, eds. Police occupational culture: new debates and directions. Oxford: Elsevier, 205-226.

Brown, J. and Heidensohn, F., 2000. Gender and policing: comparative perspectives. London: Palgrave MacMillan.

Brown, J. and Woolfenden, S., 2011. Implications of the changing gender ratio amongst warranted police officers. Policing, 5 (4), 356-364.

Burke, M.E., 1993. Coming out of the blue. London: Continuum.

Burke, M.E., 1994. Homosexuality as deviance: the case of the gay police officer. British Journal of Criminology, 34 (2), 192-203. 
Cameron, A.C. and Trivedi, P.K., 1998. Regression analysis of count data. Cambridge: Cambridge University Press.

Clements, P., 2008. Policing a diverse society. 2nd ed. Oxford: Oxford University Press.

Colvin, R., 2008. Shared perceptions among lesbian and gay police officers: barriers and opportunities in the law enforcement work environment. Police Quarterly, 12 (1), 86-101.

Colvin, R., 2012. Gay and lesbian cops: diversity and effective policing. Boulder, CO: Lynne Rienner.

Derbyshire, P., 1990. Gays and the police. Police Review, 8 (2), 1144-1145.

Dhani, A., 2012. Police service strength: England and Wales, 31st March 2012. London: Home Office.

Dorofeev, S. and Grant, P., 2006. Statistics for real-life sample surveys: non-simple random samples and weighted data. Cambridge: Cambridge University Press.

Fielding, N., Lee, R.M., and Black, G., 2008. The Sage handbook of online research methods. London: Sage.

Fyfe, N. R., 1991. The police, space and society: the geography of policing. Progress in Human Geography, 15 (3), 249-267.

GALOP, 1998. Telling it like it is: lesbian, gay and bisexual youth speak out on homophobic violence. London: GALOP.

Godwin, K., 2007. Staffordshire police: working to a different beat. Equal Opportunities Review (164), 6-9.

Hall, N., Grieve, J., and Savage, S., 2009. Policing and the legacy of lawrence. Devon: Willan.

HMIC, 1999. Police integrity: securing and maintaining public confidence. London: Home Office.

HMIC, 2003. Diversity matters. London: Home Office.

Holdaway, S., 1983. Inside the British police. Oxford: Basil Blackwell Publisher Ltd.

Holdaway, S., 2009. Black police associations. Oxford: Oxford University Press.

Holloway, S.L., 2005. Articulating otherness? White rural residents talk about gypsy-travellers. Transactions of the Institute of British Geographers, 30 (3), 351-367.

Home Office, 2006. New code of professional standards for police officers. London: Home Office.

Land, K.C., McCall, P.L., and Nagin, D.S., 1996, A comparison of Poisson, negative binomial, and semi-parametric mixed Poisson regression models with empirical applications to criminal careers data. Sociological Methods and Research, 24 (4), 387-442.

Lewisham Gay Alliance, 1992. Violence against men in Lewisham. London: Safe Neighbourhoods Unit.

Loftus, B., 2009. Police culture in a changing world. Oxford: Oxford University Press.

Macpherson, S.W., 1999. The Stephen Lawrence inquiry: report of an inquiry by Sir William Macpherson of Cluny. London: HMSO.

Manning, P.K., 1989. Occupational culture. In: W.G. Bailey, ed. Encyclopedia of police science. New York: Garland.

Mason, A. and Palmer, A., 1996. Queerbashing. London: Stonewall.

Mawby, R.I. and Yarwood, R., eds., 2010. Rural policing and policing the rural: a constable countryside? Surrey: Ashgate Publishing.

McLaughlin, E., 2007. The new policing. London: SAGE.

Meyer, I.H. and Wilson, P.A., 2009. Sampling lesbian, gay, and bisexual populations. Journal of Counselling Psychology, 56 (1), 23-31.

Moran, L., 2012. The changing landscape of policing male sexualities: a minor revolution? In: P. Johnson \& D. Dalton, eds., Policing sex, London: Routledge, 11-22.

National Advisory Group/Policing Lesbian and Gay Communities, 1999. Breaking the Chains of Hate. Manchester: NAGS.

Neal, S., 2002. Rural landscapes, representations and racism: examining multicultural citizenship and policy-making in the English countryside. Ethnic and Racial Studies, 25 (3), 442-461.

O'Neill, M. and Holdaway, S., 2007. Examining "Window Dressing": The Views of Black Police Associations on Recruitment and Training. Journal of Ethnic and Migration Studies, 33 (3), 483-500. 
Praat, F. and Tuffin, K.F., 1996. Police discourses of homosexual men in New Zealand. Journal of Homosexuality, 31 (4), 57-73.

Rabe-Hemp, C.E., 2008. POLICEwomen or PoliceWOMEN?: Doing gender and police work. Feminist Criminology, 4 (2), 114-129.

Reiner, R., 2010. The politics of the police. 4th ed. Oxford: Oxford University Press.

Robinson, A.L., 2003. The impact of police social capital on officer performance of community policing. Policing: An International Journal of Police Strategies and Management, 26 (4), 656-689.

Scarman, L., 1981. The Brixton disorders. London: HMSO.

Seabrook, M., 1992. Homosexuality and the police. New Law Journal, 4 (2), 325-326.

Sklansky, D.A., 2006. Not your father's police department: making sense of the new demographics of law enforcement. Criminology, 96 (3), 1209-1244.

Sklansky, D.A., and Marks, M., 2008. The role of the rank and file in police reform. Policing and society, $18(1), 1-6$.

Stonewall, 2008. Homophobic hate crime: the gay British crime survey 2008. London: Stonewall.

Van Maanen, J., 1973. Observations on the making of policemen. Human Organization, 32 (4), 407-418.

Ward, J., 2007. Sexualities, work and organizations. Oxon: Routledge.

Weeks, J., 2007 The world we have won: the remaking of erotic and intimate life. London: Routledge.

Williams, M. and Robinson, A.L., 2004. Problems and prospects with policing the lesbian, gay and bisexual community in Wales. Policing \& Society, 14 (3), 213-232.

Williams, M. and Robinson, A.L., 2007. Counted in! The all Wales survey of lesbian, gay and bisexual people. London: Stonewall.

Zorn, C.J.W., 1998. An analytic and empirical examination of zero-inflated and hurdle Poisson specifications. Sociological Methods and Research, 26 (3), 368-400. 